\title{
Loucuras Inofensivas
}

\author{
Jonas Madureira*
}

RESUMO: O artigo apresenta uma argumentação sobre o papel da imaginação diante da ameaça das "imagens totalitárias". A trama dos argumentos é constituída a partir da história do cidadão de Argos, contada por Erasmo de Rotterdam, e se desenvolve em dois blocos. No primeiro, explicita-se três distinções elementares: (1) imaginação e imagens prontas; (2) imaginação e equívoco; (3) imaginação e alucinação. Após as distinções, no segundo bloco, a argumentação concentra-se no papel da imaginação como uma potência que resiste às imagens prontas e aos esquemas mentais totalitários. Ao final, a crítica do sequestro da imaginação é feita à luz de alguns esclarecimentos das abordagens de Hannah Arendt e Paul Ricoeur, em especial, das abordagens referentes ao caráter homogeneizante e coletivista das ideologias.

PALAVRAS-CHAVE: Imaginação; Totalitarismo; Ideologia; Hannah Arendt; Paul Ricoeur

O que amamos está sempre longe de nós.

— Cecília Meireles

Nem toda loucura é perigosa. Na opinião de Erasmo de Rotterdam, há loucuras inofensivas, que não fazem mal a ninguém. ${ }^{1}$ Elas são uma doce ilusão que emana do nosso mundo interior e nos liberta dos pesares da vida, substituindo-os por inúmeros deleites. Para ilustrar seu ponto, o humanista holandês conta a história de um cidadão de Argos que todos os dias ia ao teatro. ${ }^{2}$ Ao chegar, acomodava-se rapidamente no assento central da arquibancada. Do palco não tirava os olhos um minuto se quer. Com júbilo incontido, demonstrava contemplar a mais esplendorosa das encenações. Ora ria, ora aplaudia com incomparável entusiasmo. O detalhe que

* Professor de Filosofia da Universidade Presbiteriana Mackenzie e de Teologia do Seminário Martin Bucer. Doutor em Filosofia pela USP com estágio na Universidade de Colônia (Alemanha). Mestre e bacharel em Filosofia pela PUC-SP.

${ }^{1}$ Cf. Erasmo de Roterdã, Elogio à loucura (São Paulo: Martins Fontes, 1846), p. 43-5 [\$38].

${ }^{2}$ Cf. Quinto Horacio Flacco, Satyras e epistolas (Porto: Casa de Cruz Coutinho, 1846), p. 98-9. 
faz da história um relato no mínimo curioso é o próprio teatro. Sempre vazio. Mas o que levaria alguém a se divertir sozinho num teatro vazio? $\mathrm{O}$ mais estranho é que, longe do teatro, o cidadão de Argos se comportava bem diferente, como um homem sóbrio, trabalhador, sensato, que cumpria rigorosamente seus compromissos, sempre bem-humorado, o tempo todo amável com a esposa, indulgente com os servos, enfim, uma pessoa ajuizada o suficiente para manter a serenidade mesmo quando era prejudicado por outros. Poder-se-ia até dizer que ele era louco, mas jamais perigoso. Todavia, seus amigos, incomodados com isso, providenciaram um medicamento para curar a loucura do amigo. Quando tomou o medicamento, logo expeliu a bile, e, com ela, as ilusões se foram. Ao cair em si, já recuperado dos efeitos da droga, o cidadão de Argos protestou: "Por Pólux! Vocês me arruinaram, meus amigos! Em vez de me curarem, tiraram-me a alegria, pois, contra minha vontade, privaram-me de tão doce ilusão".

Nada deveria nos privar da felicidade a não ser a falta de imaginação. A gravidade é tanta que, se em algum momento fôssemos impedidos de imaginar, nossa reação não seria diferente da decepção do cidadão de Argos. Ou seja, se queremos ser felizes, não podemos evitar a imaginação. Talvez não haja teólogo que tenha aprofundado a lógica da relação entre felicidade e imaginação mais do que Tomás de Aquino. Em sua monumental Suma de teologia, nas questões referentes ao entendimento humano, o Aquinate argumentou que é impossível ao homo viator, isto é, ao homem no estado da vida presente e à espera da bem-aventurança, conhecer qualquer coisa sem o recurso da imaginação. Nem mesmo Deus, a suprema porém invisível felicidade, poderia ser conhecido sem recorrermos à imaginação (cf. Summa theologiae, Ia., q. 84, a. 7). Mesmo João Calvino, teólogo por vezes acusado de iconoclastia, recomendava que, em suas homilias, os pregadores fossem verdadeiros "artesãos da palavra", habilidosos o suficiente para entrar na mente de seus ouvintes até fazê-los ver diante de si mesmos o Cristo crucificado e seu sangue escorrendo. ${ }^{3}$ Portanto, a imaginação está aí para levar o homem a lugares onde seus pés e mãos não alcançam. Nestes lugares estão as "alegrias mínimas". Em Da alegria no leste europeu e na Europa ocidental, Andrei Pleșu diz que alegrias mínimas jamais devem ser confundidas com "alegrias simples". Em suas palavras, "Uma coisa é te alegrares com um pedaço de pão quente e um copo de vinho, virando as costas para o restaurante requintado das redondezas; outra é te alegrares pura e simplesmente por teres pão e vinho"4.

Alguém poderia objetar: "Mas imagens não nos faltam hoje e, no entanto, permanecemos infelizes". É verdade. Em La parole bumiliée [A pala-

3 João Calvino, Gálatas, Efésios, Filipenses e Colossenses (São Paulo: Fiel, 2010), p. 90.

${ }^{4}$ Andrei Pleșu, Da alegria no leste europeu e na Europa ocidental e outros ensaios (São Paulo: É Realizações, 2013), p. 24. 
vra humilhada] $]^{5}$, Jacques Ellul apresentou várias provas que demonstram que vivemos numa época de imposição das imagens e desvalorização das palavras. É inegável a flagrante dominação do espírito pelo excesso de imagens. Entretanto, eu não disse que é a falta de imagens que deveria obliterar nossa felicidade, mas, sim, a falta de imaginação. Realmente, não faltam imagens para o homem contemporâneo. Basta correr os olhos por aí e logo veremos miríades e miríades de imagens, por vezes, justapostas. Contudo, essa manifestação superabundante de imagens não deveria ser entendida como excesso de imaginação, mas como um sinal da sua ausência. Explico. A supervalorização das imagens é o rastro da imaginação sequestrada. Imagens meramente dadas são semelhantes ao pensamento que não pensamos. Assim como é preciso pensar por conta própria, é preciso também imaginar por conta própria.

Ao contrário da imaginação, uma imagem pode ser escravizadora. Por ser imperiosa, Mário Ferreira dos Santos vê, na moderna supervalorização da imagem, um certo tipo de "barbárie vertical". Afinal, é mais fácil ver uma imagem que nos é dada do que construí-la com o material do nosso mundo interior. $\mathrm{Na}$ sociedade hiperimagética, celebrada por alguns como "pós-literária", o texto deu lugar às imagens. Por outro lado, é importante que se diga que a crítica do sequestro da imaginação pela supervalorização da imagem deve evitar ser pautada por uma espécie de disjunção, ou seja, a lógica do ou-ou: ou imaginação ou imagens prontas. Como diria Mário Ferreira dos Santos, não é bárbara a equilibrada acentuação de um e outro, mas o que é bárbaro é supervalorizar as imagens prontas à custa da imaginação própria. Uma imaginação livre da Síndrome de Estocolmo não está, por assim dizer, livre das imagens. Não estou defendendo um oximoro, isto é, uma visão iconoclasta da imaginação. Pelo contrário, coloco-me ao lado daqueles que lutam pela imaginação livre, desprendida da circunscrição de imagens prontas, que vêm de fora não para se juntar a nossa imaginação mas para destruí-la. Tal imaginação assemelha-se à loucura do cidadão de Argos. Uma loucura livre e inofensiva, mas que, por isso mesmo, perturba a suposta paz daqueles que consideram desprezível o ócio mais íntimo do indivíduo. O ócio inofensivo, a "loucura feliz e auspiciosa", para usar os termos de Erasmo, não é mero equívoco ou alucinação. Pelo contrário, é uma tentativa de acessar outras realidades por meio da imaginação.

Mas preciso dar um passo atrás a fim de dizer algumas coisas sobre esse tipo de "doce ilusão" que é a imaginação. A imaginação é uma ilusão que se distingue tanto do equivoco como da alucinação. O equívoco é a fantasia vivenciada por alguém que se confunde em sua percepção da realidade. Tenho um exemplo pessoal que ilustra bem o que é um equívoco e que,

${ }^{5}$ Cf. Jacques Ellul, La parole humiliée (Paris: Seuil, 1981). 
curiosamente, servirá também para explicar o que é uma alucinação. Quando morei na Alemanha, por ocasião do doutorado em filosofia, tive a oportunidade de visitar o Museum Ludwig, um museu de arte moderna e contemporânea, que fica bem ao lado da belíssima Catedral de Colônia. Na ocasião, estava ansioso para passar algum tempo diante do La gare de Perpignan, de Salvador Dali, que, com as telas de Picasso, integra a lista dos principais acervos daquele museu. $\mathrm{Na}$ intenção de apreciar demoradamente a pintura, resolvi chegar cedo-cogitava que, pela manhã, o movimento seria bem menor. Doce ilusão. Para minha surpresa, o museu já estava repleto de visitantes. E, apesar de estranhar a movimentação, prossegui com meu objetivo. Queria ver aquele quadro de qualquer jeito. Ao encontrá-lo, meu plano inicial foi por água abaixo. Deparei-me com uma senhora atônita diante dele. Resolvi esperar até que ela saísse para, talvez como ela, ter o meu momento exclusivo de contemplação. Passaram-se cerca de dez minutos e aquela senhora se mantinha inerte diante do quadro, sem ao menos piscar os olhos. Aproximei-me um pouco mais e, então, percebi que ela realmente não se mexia. Pensei comigo: "Alemães são bem intensos". Incomodado, olhei-a mais de perto e só assim percebi que se tratava de uma escultura feita de cera. Era incrível como aquilo era semelhante a uma mulher real. Foi desconcertante. Olhava para ela e, mesmo assim, não conseguia acreditar que era apenas uma boneca de cera. Ora, isso é um equívoco. Entretanto, se não houvesse ali uma mulher tampouco uma escultura de cera, ou seja, se não houvesse nenhum objeto de frente para o quadro e, mesmo assim, eu visse uma mulher, então, isso já não seria um equívoco. Pelo contrário, seria uma alucinação. Percebe a diferença? Tanto o equívoco como a alucinação são fruto de um erro causado, ou por uma falsa percepção, ou por uma disfunção psíquica. Em contrapartida, a imaginação não é um erro, mas uma capacidade de criar uma ilusão com a finalidade de acessar outra realidade, o nosso mundo interior. Escrever um romance ou ler um conto fantástico, por exemplo, não é um erro, mas uma experiência libertadora. Aliás, a palavra é uma das forças que podem libertar a imaginação da escravidão das imagens prontas. Sobre isso, C. S. Lewis disse algo valiosíssimo.

Queremos ver com outros olhos, fantasiar com outras imaginações, sentir com outros corações (...) O homem que se contenta em ser apenas ele mesmo e, portanto, ser menos, vive numa prisão. Meus próprios olhos não são suficientes para mim, verei por meio dos olhos de outros. A realidade, mesmo vista por meio dos olhos de muitos, não é suficiente. Verei o que os outros inventaram. Até mesmo os olhos de toda a humanidade não são o bastante. Lamento que os animais não possam escrever livros. Ficaria contente em saber que aparência têm as coisas para os olhos de um rato ou de uma abelha. Ainda mais contente ficaria em perceber o mundo olfativo, 
impregnado com todas as informações e emoções que contém para um cão. A experiência literária cura a ferida da individualidade sem arruinar seu privilégio. Há emoções de massa que também curam a ferida, mas destroem o privilégio. Nelas, nossos seres isolados fundem-se entre si, e afundamos de volta à subindividualidade. Mas lendo a grande literatura, torno-me mil homens e ainda permaneço eu mesmo. ${ }^{6}$

A pobreza espiritual é muitas vezes o resultado de um senso de que não podemos perder tempo com amenidades, como, por exemplo, ler literatura, apreciar uma ópera, assistir a uma peça teatral, ouvir uma sinfonia ou um concerto de jazz, etc. A consciência sequestrada por uma imagem totalitária escandaliza-se quando percebe um espírito livre, que gasta longas horas em um teatro vazio, contemplando e celebrando apenas os frutos da sua imaginação. Atarantadas por causa da felicidade dos que ousam imaginar por conta própria, as mentes ressentidas reduzem suas vidas a uma obsessão: arruinar a alegria daqueles cuja felicidade não se reduz a meras obrigações diárias. Essas mentes ressentidas são como prisioneiros que um dia contemplaram além das sombras, mas, agora, mesmo livres, escolhem a prisão. Regressam, sabe-se lá o porquê, para o fundo da caverna, não para libertar outras almas, mas para se acomodarem no mesmo lugar de antes. A única diferença é que agora o cativeiro não é mais feito de correntes, mas do próprio amor que elas têm pelas sombras. O que fez estes pobres cães voltarem ao seu próprio vômito? $\mathrm{O}$ totalitarismo das sombras. Não disse autoritarismo, mas totalitarismo das sombras.

Hannah Arendt, filósofa judia e alemã, usou o termo "totalitarismo" para designar toda arbitrariedade justificada por uma lei superior não positiva. ${ }^{7}$ Apesar do uso irrestrito que se faz do termo, convém relembrar seu sentido original, uma vez que não são poucos os que confundem totalitarismo com despotismo, tirania e ditadura, e, portanto, não conseguem compreender o que o termo de fato significa. Para desfazer o imbróglio, é necessário compreender, antes de mais nada, o caráter inédito do totalitarismo. Não há precedente na história antiga e medieval — sequer há um caso de desdobramento do tipo "o totalitarismo surgiu da tirania". Para Arendt, o totalitarismo é uma espécie nova e totalmente diferente de administração do poder. Não é e nem poderia ser confundido com o domínio tirânico, uma vez que não se sustenta apenas na arbitrariedade de um governante e em sua respectiva superioridade sobre as camadas populares. A distinção entre os domínios tirânico e totalitário justifica-se pelo fato de que este não opera fora da lei, justamente o oposto daquele, cuja característica principal é a arbitrariedade.

${ }^{6}$ C. S. Lewis, Um experimento na crítica literária (São Paulo: Editora Unesp, 2009), p. 118-121.

${ }^{7}$ Cf. Hannah Arendt, Origens do totalitarismo (São Paulo: Companhia das Letras, 1989); ver também A dignidade da politica: ensaios e conferências (Rio de Janeiro: Relume-Dumará, 1993). 
Que leis são essas que "legitimam" o governo totalitário? O totalitarismo busca obedecer de forma rigorosa e inequívoca às leis que Arendt chama de "leis da Natureza" ou "leis da História". Ora, do ponto de vista totalitarista, essas leis são legitimamente superiores em relação às leis positivas. Se voltarmos no tempo, como sugere Arendt, encontrar-se-ão, de um lado, Hitler discursando sobre a doutrina da "raça pura" com base em supostas "leis da Natureza" e, do outro, Stalin edificando o materialismo históricodialético por meio de supostas "leis da História". Ambos, subjugando as leis positivas de suas respectivas nações às suas próprias doutrinas, e, por isso, reduzindo o caráter fixo da lei positiva aos movimentos de uma particular Weltanschaunng (visão de mundo) ou Weltbild (imagem de mundo).

Agora, por que usar Hitler e Stalin como imagens emblemáticas do governo totalitário? De acordo com Arendt, o nazismo e o comunismo tornaram-se exemplos categóricos de regimes totalitários por trazerem em si mesmos a característica elementar que marca com precisão a singularidade histórica do totalitarismo. Basta analisar esses regimes e ver-se-á que a sua singularidade se deve ao fato de que, além de criar instituições políticas inteiramente novas, esses governos totalitários destroem, ao mesmo tempo, a pluralidade das tradições culturais, legais e políticas de um povo, substituindo o sistema partidário não apenas por um regime unipartidário, mas por aquilo que Arendt chamou de "movimento de massa". Em outras palavras, o totalitarismo possui o poder de transformar as classes em massas, estabelecendo, assim, uma sociedade completamente homogeneizada.

Como se dá o processo de homogeneização? Arendt argumenta que os regimes totalitários costumam adotar uma certa ideologia, como, por exemplo, o arianismo de Hitler que se pautava na teoria da evolução das espécies de Darwin, ou o materialismo histórico-dialético de Stalin que se amparava na teoria da mais-valia de Marx. O curioso é perceber que essas ideologias, além de se firmarem em uma suposta harmonia entre ciência e filosofia, se baseavam também em movimentos evolucionistas. Tanto o nazismo como o comunismo pressupõem uma evolução, seja da Natureza, seja da História. Nesse caso, o próprio termo "lei" perdeu o seu sentido, a sua força. O estatuto da lei não é mais o da imutabilidade, mas o oposto. Agora, as leis, consideradas máximas, mudam porque a Natureza está em constante evolução ou porque a História está em pleno progresso. Nisso, Arendt vê consequências drásticas que não poderiam ter como resultado outra coisa senão o terror. Afinal, que outro resultado poderia ser obtido a partir de uma situação em que as leis máximas de um povo perdem seu caráter de imutabilidade?

Além do terror, como uma espécie de acicate que domestica os homens, a fim de liberar as forças da Natureza ou da História, Arendt descreve outra fonte que alimenta o poder homogeneizante do totalitarismo, a 
saber, a ideologia. Em Interpretação e ideologias, Paul Ricoeur argumenta que um dos traços marcantes da ideologia é seu dinamismo. ${ }^{8} \mathrm{Em}$ suas palavras, "ela depende daquilo que poderíamos chamar de uma teoria da motivação social". De acordo com Ricoeur, a ideologia é, para a vida pública, aquilo que é, para a vida privada, um motivo. O motivo é aquilo que justifica a união das massas e compromete o indivíduo com a coletividade. Assim, a ideologia é uma motivação social que justifica e compromete um indivíduo com a massa - justifica-se na medida em que assegura ou avaliza o ato e compromete-se na medida em que o ato realiza o motivo.

Ora, como a ideologia preserva seu dinamismo? Segundo Ricoeur, "toda ideologia é simplificadora e esquemática". Salvo as divergências que existem entre Ricoeur e Arendt, pode-se afirmar que, nesse caso, Arendt concordaria com Ricoeur, uma vez que, para ambos, o pensamento ideológico tende a arrumar os fatos sob a forma de um processo absolutamente simples e esquemático; processo este que se inicia a partir de uma premissa aceita axiomaticamente e tudo o mais sendo deduzido dela. Outra congruência é que ambos os pensadores veem nas ideologias um código interpretativo que incita as pessoas a tomarem a imagem pelo real, o reflexo pelo original. Contudo, a peculiaridade da crítica de Arendt está na tentativa de esclarecer a razão de o pensamento ideológico se tornar uma fonte homogeneizante do totalitarismo. Isso lhe dá condições de ver no código interpretativo de uma ideologia não apenas uma hermenêutica da realidade, como afirma Ricoeur, mas uma mentalidade conspirativa em que "a realidade não é mais compreendida nos seus próprios termos”. Em suma, para Arendt, todo pensamento ideológico vai contra a realidade na medida em que o mundo real é substituído por uma imagem de mundo. ${ }^{9}$

Uma última correlação entre Paul Ricoeur e Hannah Arendt pode ser estabelecida a partir de uma expressão bastante interessante de Ricoeur: "a ideologia opera atrás de nós”. O que isso significa? Que a ideologia, como mentalidade conspirativa e totalizante, sufoca o pensamento e a imaginação por conta própria, ao nivelar as diversas manifestações do espírito de uma comunidade a partir de uma imagem pronta. Essa sopa coletivista, digamos assim, não é uma comunidade, mas a soma de indivíduos perdidos numa coletividade. Uma vez que as ideologias possuem a pretensão de propor

\footnotetext{
${ }^{8}$ Cf. Paul Ricoeur. Interpretação e ideologias (Rio de Janeiro: Francisco Alves, 1990).

${ }^{9} \mathrm{Um}$ exemplo dessa vontade de alteração da realidade pela ressignificação da realidade pode ser claramente visto em Problemas de gênero, de Judith Butler. Nesse ensaio, ou agrupamento de ensaios, Butler pressupõe que a discussão sobre identidade e gênero, por exemplo, não deveria ser pautada por uma teoria da realidade, mas, sim, por uma teoria da representação. Em suas palavras, "Os domínios da 'representação' política e linguística estabeleceram a priori o critério segundo o qual os próprios sujeitos são formados". Judith Butler, Problemas de gênero: feminismo e subversão da identidade (Rio de Janeiro: Civilização Brasileira, 2016), p. 18.
} 
uma explicação total, ou seja, tudo é explicado a partir de uma imagem pronta e totalizante, elas inibem automaticamente o pensamento e a imaginação. Em Origens do totalitarismo, Arendt afirma que o perigo de trocar a necessária segurança do pensamento e da imaginação pela explicação total de uma ideologia e sua Weltanschanung não é tanto o risco de ser iludido por alguma suposição geralmente vulgar e sempre destituída de crítica, mas, sim, o risco de trocar a liberdade, inerente à capacidade da imaginação, pela camisa de força de uma imagem que não tem outra finalidade a não ser subjugar e estrangular um indivíduo, tal como um sequestrador faria com sua vítima. Quando a imaginação de um povo é sequestrada, a arte padece, o povo padece, o indivíduo padece. E o pior, todos padecem nas mãos de almas nanicas, coletivistas, que vivem em mundos minúsculos e demasiado sufocantes. Para nossa sorte, as loucuras inofensivas estão aí para libertar almas robustas, quer dizer, "inofensivas" pelo menos até as almas nanicas não suportarem mais a alegria dos que se divertem à custa delas. 


\section{Referências bibliográficas}

Butler, Judith. Problemas de gênero: feminismo e subversão da identidade. Rio de Janeiro: Civilização Brasileira, 2016.

Calvino, João. Gálatas, Efésios, Filipenses e Colossenses. São Paulo: Fiel, 2010.

Ellul, Jacques. La parole bumiliée. Paris: Seuil, 1981.

Erasmo de Roterdã. Elogio à loucura. São Paulo: Martins Fontes, 1846.

Hannah Arendt. Origens do totalitarismo. São Paulo: Companhia das Letras, 1989.

_. A dignidade da política: ensaios e conferências. Rio de Janeiro: RelumeDumará, 1993.

Lewis, C. S. Um experimento na crítica literária. São Paulo: Editora Unesp, 2009.

Pleșu, Andrei. Da alegria no leste europeu e na Europa ocidental e outros ensaios. São Paulo: É Realizações, 2013.

Quinto Horacio Flacco. Satyras e epistolas. Porto: Casa de Cruz Coutinho, 1846.

Ricoeur, Paul. Interpretação e ideologias. Rio de Janeiro: Francisco Alves, 1990. 


\title{
Inofensive Madnesses
}

\begin{abstract}
This article offers an argument concerning the role of the imagination facing the threat of "totalitarian images". The argument's is weaved from the story of the citizen of Argos told by Erasmus of Rotterdam, and develops into two blocs. In the first bloc, three elementary distinctions are made, between: (1) imagination and ready-made images; (2) imagination and equivocation; (3) imagination and hallucination. Following the distinctions, in the second bloc the argument focuses on the role of the imagination as a potency that resists ready-made images and totalitarian mental schemes. In the end, a criticism of the kidnapping of the imagination is articulated in light of some of Hannah Arendt's and Paul Ricoeur's approaches, especially as regards the homogenizing and collectivist character of ideologies.
\end{abstract}

KEYWORDS: Imagination; Totalitarianism; Ideology; Hannah Arendt; Paul Ricoeur 